\title{
Microstructural characterization of AISI 431 martensitic stainless steel laser-deposited coatings
}

\author{
I. Hemmati $\cdot$ V. Ocelík $\cdot$ J. Th. M. De Hosson
}

Received: 24 October 2010/Accepted: 28 December 2010/Published online: 12 January 2011

(C) The Author(s) 2011. This article is published with open access at Springerlink.com

\begin{abstract}
High cooling rates during laser cladding of stainless steels may alter the microstructure and phase constitution of the claddings and consequently change their functional properties. In this research, solidification structures and solid state phase transformation products in single and multi layer AISI 431 martensitic stainless steel coatings deposited by laser cladding at different processing speeds are investigated by optical microscopy, Scanning electron microscopy (SEM), energy dispersive spectroscopy (EDS), orientation imaging microscopy (OIM), ternary phase diagram, Schaeffler and TTT diagrams. The results of this study show how partitionless solidification and higher solidification rates alter the microstructure and phase constitution of martensitic stainless steel laser deposited coatings. In addition, it is shown that while different cladding speeds have no effect on austenitemartensite orientation relationship in the coatings, increasing the cladding speed has resulted in a reduction of hardness in deposited coatings which is in contrast to the common idea about obtaining higher hardness values at higher cladding speeds.
\end{abstract}

\section{Introduction}

Austenitic stainless steels are being extensively used for structural components to be employed in corrosive environments. However, increasing number of applications requires superior friction and wear behavior in addition to

I. Hemmati · V. Ocelík $(\bowtie) \cdot J$ J. Th. M. De Hosson Department of Applied Physics, Materials innovation institute (M2i), University of Groningen, Nijenborgh 4,

9474 AG Groningen, The Netherlands

e-mail: v.ocelik@rug.nl corrosion resistance [1, 2]. Laser cladding by powder injection is an attractive surface engineering method to improve the wear resistance of austenitic stainless steels by producing high quality, dense, metallurgically bonded and thick coatings with minimal heat input into the work piece. This improvement can be obtained by coating of new parts or refurbishment of damaged components with materials having excellent combination of corrosion resistance and hardness such as martensitic stainless steels.

As the heat input during laser cladding is very localized, cooling rates during solidification and subsequent cooling in solid state are usually very high. It has been shown before that high cooling rates during solidification have altered the microstructures in stainless steel weld deposits $[3,4]$. In other words, rapid solidification of stainless steels may produce microstructures different from those observed during conventional solidification with differences in mode of solidification, scale of microstructural features and solute segregation patterns. These discrepancies can strongly affect the final mechanical, chemical and technological properties of the coatings [3, 4].

In the case of laser-deposited coatings, it is generally believed that faster cooling rates obtained at higher cladding speeds produce finer microstructures with increased hardness values [5]. While this idea is well known for alloy systems including precipitation hardening, it is not studied for alloys in which the main strengthening mechanism is martensitic transformation. In this investigation, single and multi-layer coatings of AISI 431 martensitic stainless steel was deposited on AISI 304 austenitic stainless steel by laser cladding at various speeds. The objective of this study is to explain in detail the microstructural features and phase constitutions resulting from rapid solidification and the possible changes in the orientation relationship between solid state transformation products during subsequent solid 
state cooling as the starting point to understand and control the functional properties of this type of coating. In addition, the implications of microstructural changes on hardness of clad layers are discussed.

\section{Experimental procedures}

Commercial 42C powder from Sulzer Metco (equivalent to AISI 431) with particle size in the range of -140 to +325 mesh was deposited on AISI 304 rods with $40 \mathrm{~mm}$ diameter using a continuous wave IPG fiber laser with wavelength of $1.07 \mu \mathrm{m}$ and variable power up to $3.3 \mathrm{~kW}$. The laser beam was defocused to obtain a laser spot size of $3.3 \mathrm{~mm}$ on the surface in all experiments. The overlapping between subsequent tracks was $30 \%$ and thickness of single and five layer deposits were almost 1 and $4 \mathrm{~mm}$, respectively. Chemical compositions of the cladding and substrate materials are presented in Table 1. Powder feeding system consisted of Metco Twin 10C powder feeder, argon as carrier and shielding gas and ALOtec Dresden $\mathrm{GmbH}$ $\mathrm{Cu}$-based side cladding nozzle with cyclone and 2-mm nozzle opening. Single layer and five layer samples were deposited at scanning speeds $(V)$ of $5,25,58$, and $117 \mathrm{~mm} / \mathrm{s}$. In multi-layer deposits, the time between deposition of subsequent layers was $5 \mathrm{~s}$. Solidification structure was studied by optical microscopy on samples prepared by standard mechanical grinding/polishing and etched with Kalling 1 reagent for 5-10 s.

Solid state transformation structures were studied by optical microscopy and Philips XL30 FEG scanning electron microscope (SEM) equipped with orientation imaging microscopy (OIM). As the distorted lattice of untempered martensite makes it difficult to get good quality electron back scatter diffraction (EBSD) patterns, using a suitable sample preparation method which produces minimum surface relief was essential. In this research, surface preparation procedure recommended by Struers Co. for EBSD analysis of ferrous alloys was employed [6]. This procedure consists of mechanical grinding with SiC-paper number 320 and $9 \mu \mathrm{m}$ diamond suspension, polishing with 3,1 , and $0.25 \mu \mathrm{m}$ diamond suspensions and final polishing with OP-AA suspension. Using this preparation method, percentage of indexed data was higher than $95 \%$ in all of the OIM measurements. EBSD data were obtained by TSL

Table 1 Nominal composition of the coating and substrate materials (wt\%) [8]

\begin{tabular}{llllll}
\hline Alloy & $\mathrm{C}$ & $\mathrm{Mn}$ & $\mathrm{Si}$ & $\mathrm{Cr}$ & $\mathrm{Ni}$ \\
\hline AISI 431 & 0.2 & 1 & 1 & $15-17$ & $1.25-2.5$ \\
AISI 304 & 0.08 & 2 & 1 & $18-20$ & $8-10.5$ \\
\hline
\end{tabular}

OIM Data Collection 5 and analyzed by TSL OIM Analysis 5.31 software. Previous research [7] showed that choosing other crystal symmetries than bcc for indexing martensite EBSD patterns will produce poor results and consequently, gamma $(\gamma)$ and alpha $(\alpha)$ Iron were included as the constituent phases in all of the OIM analyses in this research.

Energy dispersive spectroscopy (EDS) elemental mapping was employed to analyze the distribution of alloying elements and their possible partitioning. EDS maps of $\mathrm{Cr}$, $\mathrm{Ni}, \mathrm{Si}$, and $\mathrm{Mn}$ were obtained at $20 \mathrm{kV}$ and map of $\mathrm{C}$ was collected at $4 \mathrm{kV}$ accelerating voltage. Ternary phase diagram, Schaeffler and TTT diagrams were employed to analyze the experimental findings and determine the effects of rapid solidification on deviations from equilibrium state.

\section{Results and discussion}

\section{Solidification structures}

Figure 1 shows the three distinct microstructures which could be identified in the deposits. Observation of interfacial regions (Fig. 1a) showed that a thin layer of planar growth was present at all interfaces with an extension of around $20 \mu \mathrm{m}$. This plane growth zone became unstable as solidification proceeded and broke down into cellular dendrites within short distances from the interface. As a result, cellular dendrites formed the majority of solidification microstructures. In multi layer deposits, a columnar to equiaxed transition (CET) occurred at the top of deposits resulting in a thin layer of equiaxed grains (Fig. 1b).

To explain the observed microstructural changes, it is necessary to know the parameters which control the solidification structure. These parameters are mainly solidliquid interface growth rate $R$ and temperature gradient in the melt $G$. The $G / R$ ratio determines the solidification mode and the $G \cdot R$ product controls scale of the solidified structure [9]. CET takes place when nucleation of equiaxed grains occurs in the liquid ahead of the columnar structure. In laser cladding, this will not happen unless the ratio of $G / R$ is lower than some critical value [10]. As can be seen in Fig. 2, by lowering the $G / R$ ratio, solidification structure changes from planar to cellular and then columnar and equiaxed dendrites. In single layer coatings, only the transition from planar to cellular and columnar dendrites happened but in five layer deposits, all of the transitions were visible. These changes imply that during solidification, $G / R$ ratio was not constant. Previous research [4] shows that in laser solidification treatments the $G / R$ is infinite at the bottom of the melt pool which translates into a planar growth layer but rapidly decreases and as a result, structure of laser claddings mostly consists of columnar growth of dendrites [4]. 


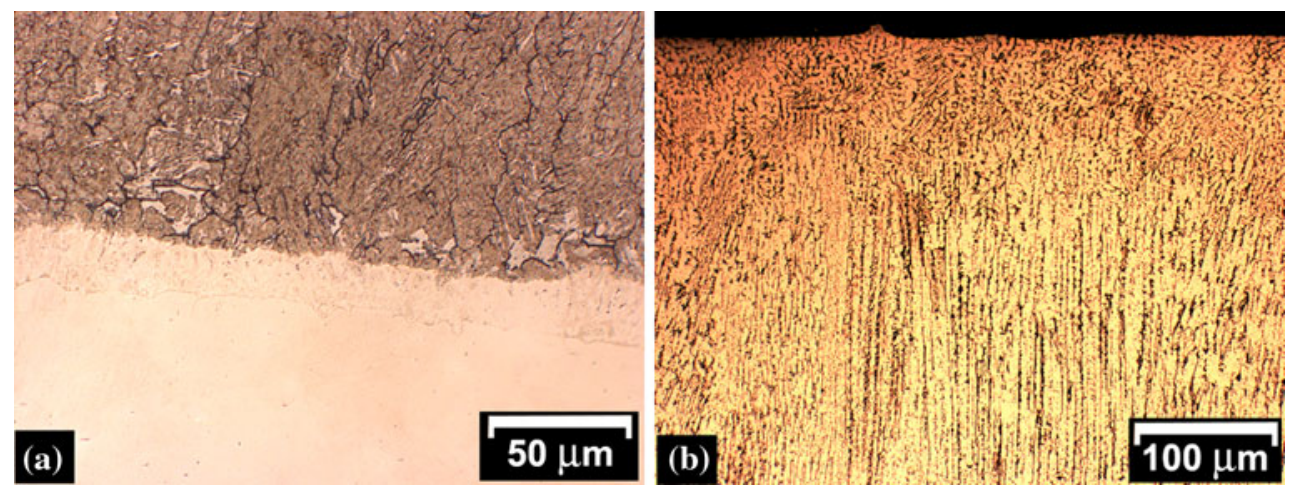

Fig. 1 Solidification structures of the coatings revealed by optical microscopy: a planar growth at substrate-coating interface, $\mathbf{b}$ cellular dendritic structure with columnar to equiaxed transition at top of the deposit ((a) transversal and (b) longitudinal cross sections)

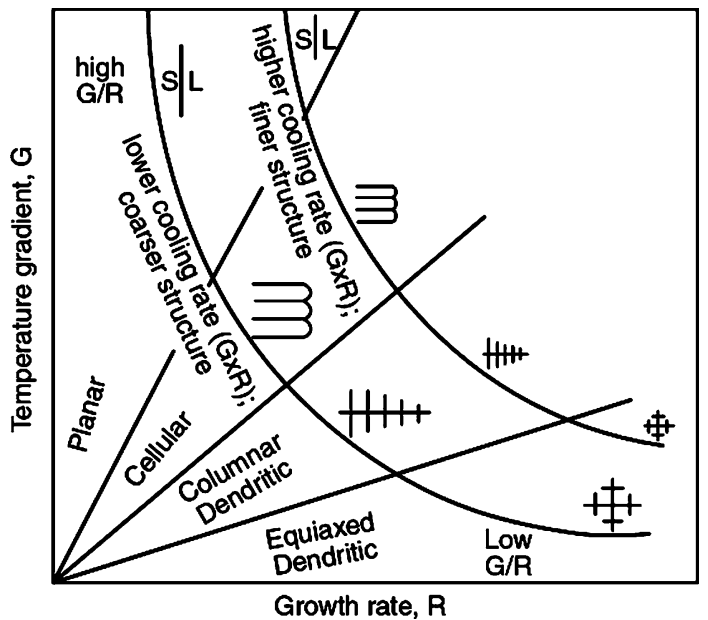

Fig. 2 Effect of $G$ and $R$ on morphology and scale of solidification structures [9]

Recent studies $[11,12]$ confirmed that in multi layer laser claddings with constant power, temperature, and size of the melt pool increase from each layer to the next because of heat accumulation. This was also observed in this study in which size of the melt pool in multi layer deposits (measured by optical microscopy after sectioning) was almost doubled from the first to the fifth layer. In fact, this heat accumulation reduces the high temperature gradients typically associated with columnar microstructures and provides the opportunity for a transition from columnar to equiaxed structure [11].

Increasing the cladding speed (i.e., increasing the solidification rate) did not affect the microstructural features such as epitaxial growth across subsequent layers or transitions in the solidification mode but scale of the dendritic structures was significantly refined as is obvious by the reduction of cell spacing at higher cladding speeds as shown in Fig. 3. Higher cladding speeds produced smaller cell spacing with values down to around $9 \mu \mathrm{m}$ in five-layer

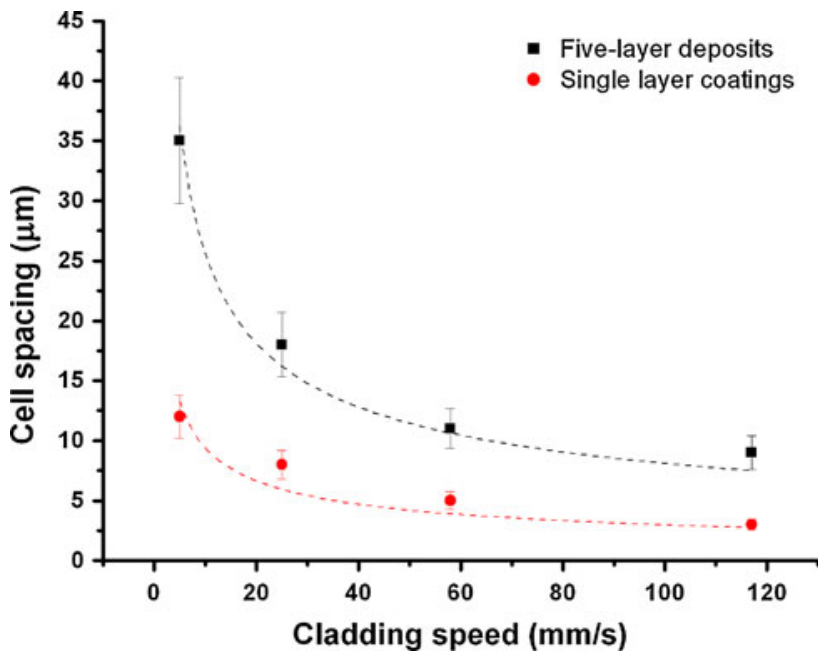

Fig. 3 Effect of cladding speed on cell spacing of single and multi layer deposits. Dashed lines show the fits for $V^{-0.5}$ dependence

and $3 \mu \mathrm{m}$ in single layer deposits. This can be explained by the fact that growth rate is a direct function of cladding speed and higher growth rates are obtained at higher deposition velocities. A variation of $15 \%$ is included in the data of Fig. 3 to account for changes in cell spacing values from bottom to top of the coating because of local variations in solidification conditions [13]. The difference in the cell spacing values of single and multi-layer deposits in spite of their similar cladding speeds can be attributed to the heat accumulation in multi-layer claddings as explained above but in both cases, cell spacing followed the empirical power law of cell spacing $V^{-0.5}$ reported previously [14].

\section{Solidification phases}

The connection between chemical composition of stainless steel laser depositions and their equilibrium phase constitution can be obtained by equilibrium diagrams such as 
Schaeffler and ternary phase diagrams. Figure 4 shows the composition of AISI 431 on Schaeffler diagram [15] and on a section of ternary $\mathrm{Fe}-\mathrm{Cr}-\mathrm{Ni}$ phase diagram at the latest stage of solidification $\left(1,400{ }^{\circ} \mathrm{C}\right)$ calculated by 3D Demo system for Ternary Phase Diagrams from Japan Science and Technology Corporation. A dilution of around $10 \%$ from substrate was taken into account in calculating the position of AISI 431 on the above-mentioned diagrams but because of big differences in the amounts of $\mathrm{C}, \mathrm{Cr}$ and $\mathrm{Ni}$ between substrate and coating, $\mathrm{Cr}_{\text {eq. }}$ and $\mathrm{Ni}_{\text {eq. }}$ values with and without dilution were approximately the same and this allowed neglecting dilution from substrate and having the same position on diagrams for both single and multi layer deposits.

Based on these diagrams, equilibrium solidification of AISI 431 is a mixed austenitic-ferritic solidification which finally results in around $10 \%$ delta ferrite $(\delta)$ along with martensite and retained austenite at room temperature. While these diagrams are reliable for predicting structures at cooling rates close to equilibrium, numerous previous researches [3, 16-19] showed that solidification and solid state cooling rates have a significant effect on the final microstructures, thus making it unreliable and even impossible to predict the phase constitution of rapidly cooled stainless steels from the conventional diagrams. This unreliability was shown in the current research in terms of the amount and distribution of $\delta$ in claddings deposited at different speeds. Figure 5 shows the optical micrographs of 5-layer samples deposited with cladding speeds of 5 (Fig. 5a) and $117 \mathrm{~mm} / \mathrm{s} \mathrm{(Fig.} \mathrm{5b).} \mathrm{It} \mathrm{can} \mathrm{be} \mathrm{seen,} \mathrm{especially}$ at track overlapping areas, that by increasing the cladding speed less $\delta$ (visible as white islands) was formed. In addition, distribution of $\delta$ is not homogenous and as shown in Fig. 6, while little amounts of $\delta$ are present at interdendritic areas; huge quantities are formed at the beginning of each solidification step, i.e., at substrate-coating interface or in remelted parts of the previous track. A point which should be emphasized here is that high cooling rates after solidification tends to suppress the solid state transformation of $\delta$ to $\gamma$. Consequently, concentration of $\delta$ in some areas should be a result of solidification step.

Studying the solute redistribution in the overlapping areas (which contain considerable quantities of both $\gamma$ and
Fig. 4 a Schaeffler diagram [15] and $\mathbf{b}$ section of ternary $\mathrm{Fe}-\mathrm{Cr}-\mathrm{Ni}$ phase diagram. Composition of AISI 431 is shown with a dot in each diagram
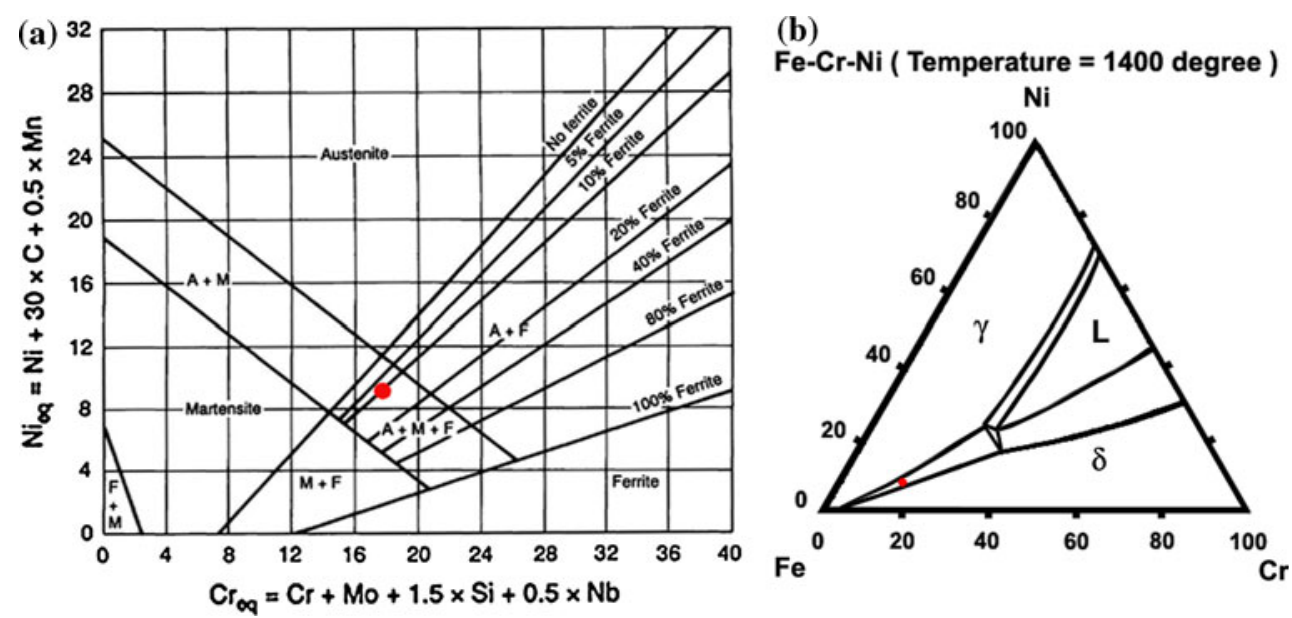
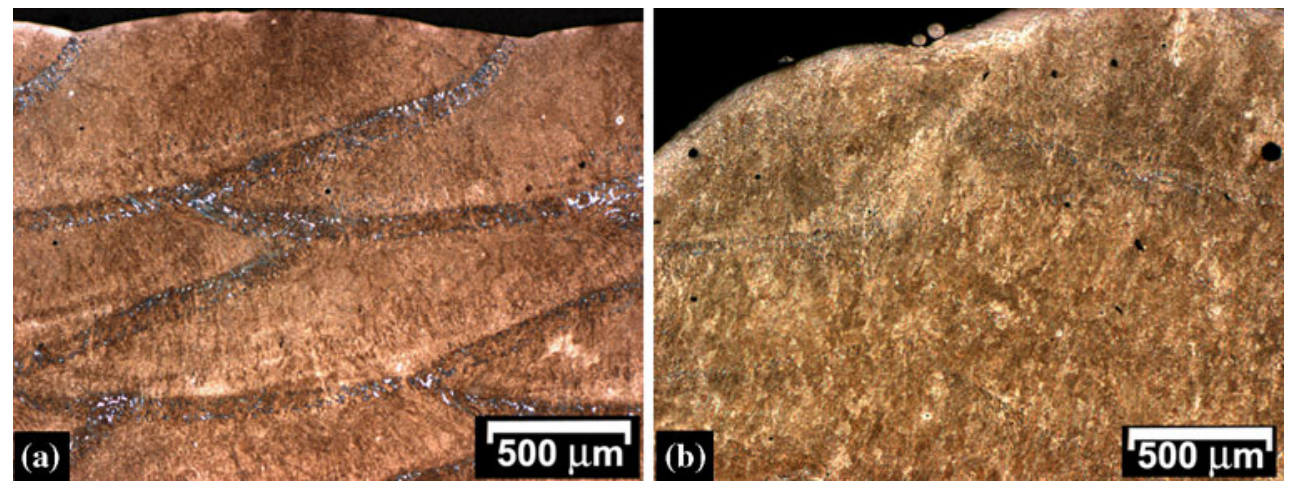

Fig. 5 Reduction in the amount of $\delta$ with increasing cladding speed: a 5 and b $117 \mathrm{~mm} / \mathrm{s} . \delta$ phase appears as bright islands mostly at track interfaces 


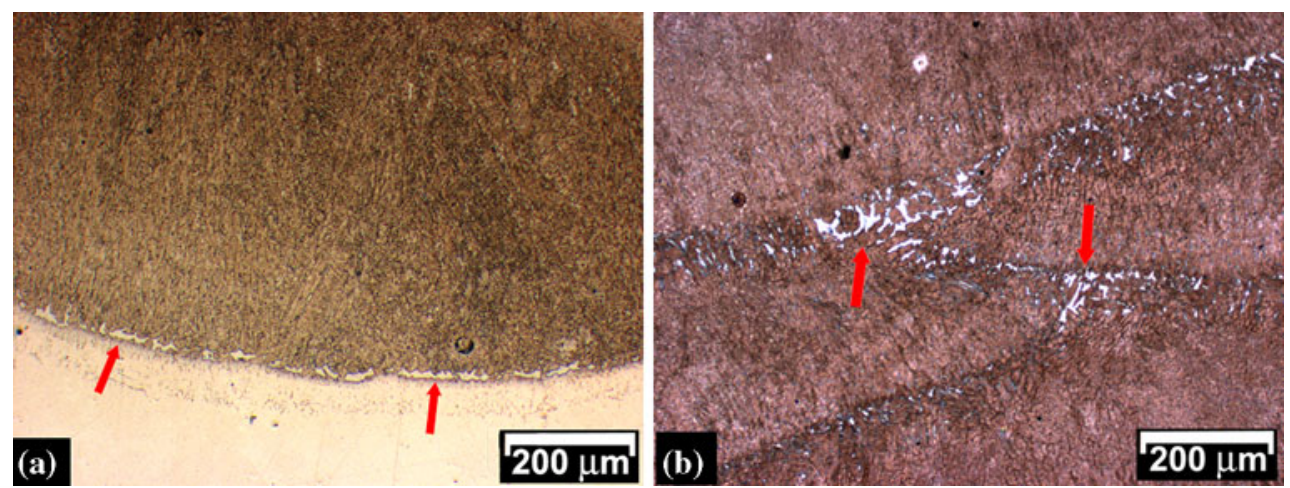

Fig. 6 Distribution of $\delta$ (bright islands shown by arrows): a at substrate-cladding interface and $\mathbf{b}$ at track overlapping areas
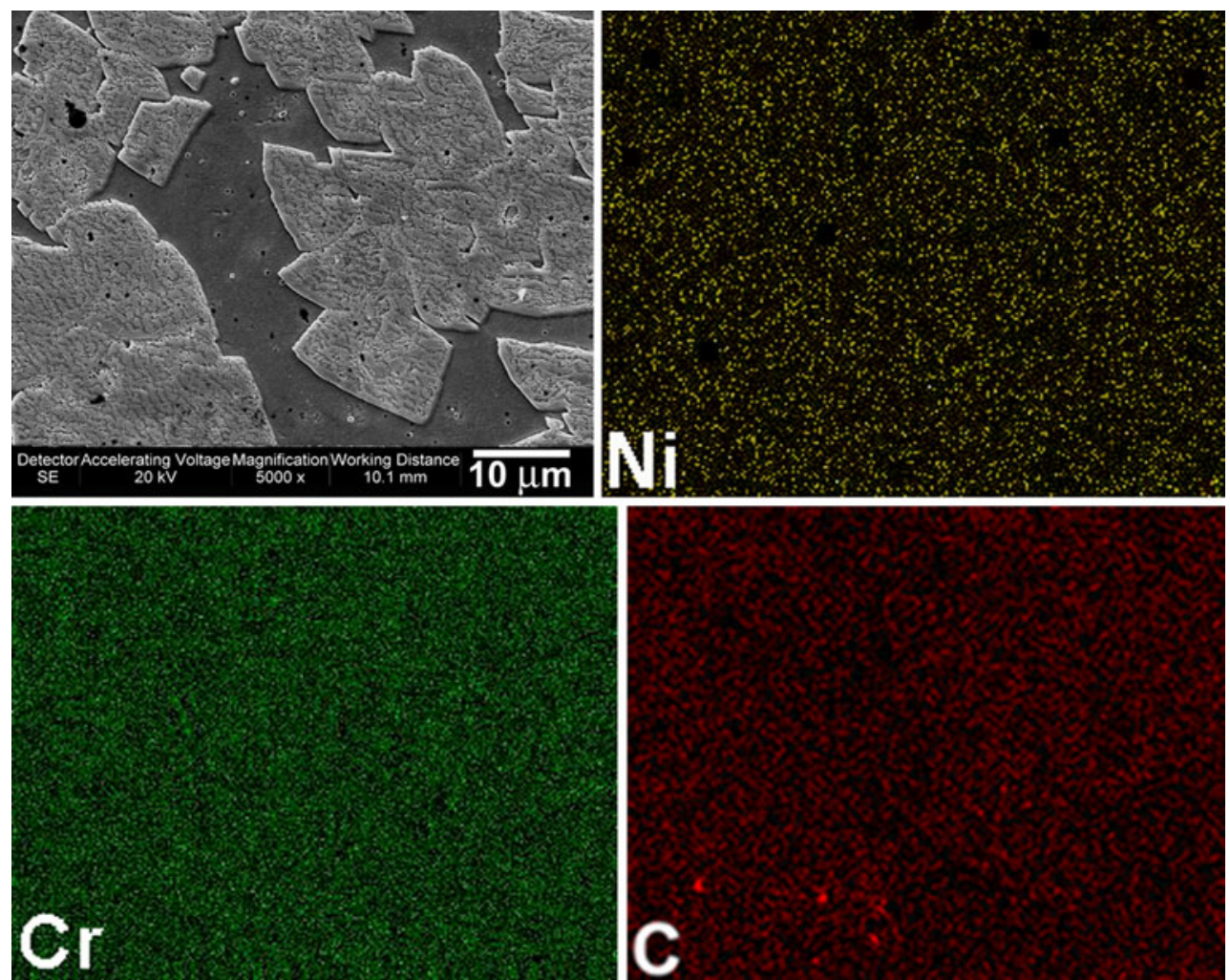

Fig. 7 SEM micrograph of a dual phase area in AISI 431 laser deposit and the EDS spectral maps showing the distribution of Ni, Cr, and C in that area

$\delta$ ) by EDS spectral mapping showed that even in the lowest cladding speed, there was no detectable partitioning of alloying elements between these two phases. Figure 7 shows the EDS maps for $\mathrm{Cr}$, Ni (obtained at $20 \mathrm{kV}$ ), and C (obtained at $4 \mathrm{kV}$ ) as the main alloying elements in AISI 431 stainless steel. Uniformity of chemical composition in dual phase areas suggests that solidification of these coatings occurred in a partitionless manner probably because of the high cooling rate and its associated undercooling during the laser deposition process.
Taking the high cooling rate and partitionless solidification into account, the liquidus line in phase diagram will not be the start of solidification anymore and instead, $T_{\mathrm{o}}$ line should be considered as the beginning of solidification as shown in Fig. 8. $T_{\mathrm{o}}$ line is the loci of $T_{\mathrm{o}}$ temperatures at which the new phase can appear with a net decrease in free energy at the same composition as the parent phase. In fact, $T_{\mathrm{o}}$ line defines the boundary below which diffusionless transformation is possible. Below $T_{\mathrm{o}}$, free energy of the single phase $\gamma$ or $\delta$ is lower than the free energy of 


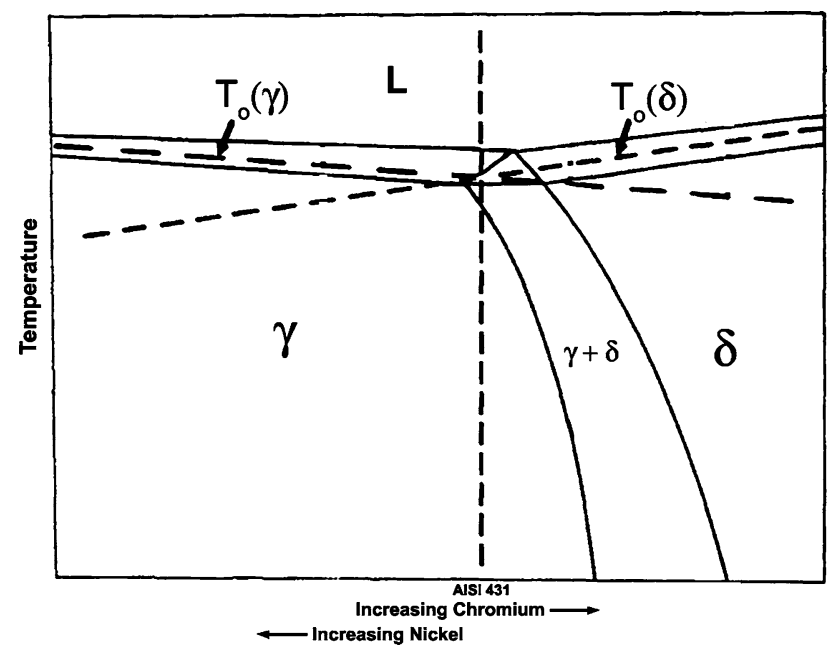

Fig. 8 Position of AISI 431 composition in ternary phase diagram during partitionless solidification $[3,16]$

undercooled liquid and partitionless solidification will be theoretically possible [3]. $T_{\mathrm{o}}$ curve is located between the liquidus and solidus lines of equilibrium phase diagram (Fig. 8) in which the data from references [3] and [18] are combined to show the composition of AISI 431 in the phase diagram with $T_{\mathrm{o}}$ lines. In this case, solidification structure depends on whether the $T_{\mathrm{o}}$ line (or its extension) of $\gamma, \delta$ or both of them is crossed by the undercooled melt and relative quantity of $\gamma$ and $\delta$ is governed by the difference in $T_{\mathrm{o}}$ temperatures of the two phases [16]. As can be seen in Fig. 8, $T_{\mathrm{o}}$ temperatures of $\gamma$ and $\delta$ for AISI 431 composition are very close and this means that if the undercooled liquid crosses the $T_{\mathrm{o}}$ lines, both phases will form in similar quantities. This idea is confirmed by micrographs of Fig. 6 which show that at the beginning of each solidification stage, $\gamma$ and $\delta$ phases were formed in similar proportions. It can be concluded that the undercooling achieved during rapid solidification was sufficient to bring the liquid metal below both $T_{\mathrm{o}}$ lines making it possible for both phase to nucleate.
Figure 6 also shows that after a short time, $\gamma$ outgrew $\delta$ and became the primary solidification phase. This can be attributed to the faster growth kinetics of $\gamma$ in comparison to $\delta$ which was observed in several previous research works on welding of stainless steels [3, 16, 20]. It seems that while partitionless solidification provides the opportunity for both $\gamma$ and $\delta$ to nucleate at initial stages of solidification, more favorable growth kinetics of $\gamma$ (especially at higher solidification rates) dominates the rest of solidification resulting in a mostly austenitic structure with isolated block of $\delta$ at the interfaces and occasional stringers at interdendritic areas.

\section{Characteristics of the solid state transformation product}

It is expected that by changing the cladding speed, not only the solidification rate changes, but also cooling rate in solid state is affected and this can have implications on solid state transformation products. According to TTT diagram of the AISI 431 stainless steel [21], this type of steel has a very high hardenability and to form any transformation product other than martensite, such slow cooling rates are needed that take $10^{3}-10^{4} \mathrm{~s}$ to reach around $600^{\circ} \mathrm{C}$ from austenitizing temperature. Under our processing conditions, having these slow cooling rates is virtually impossible and only the transformation of austenite to martensite can occur. Optical microscopy and SEM microstructural investigation of the samples deposited at different cladding speeds revealed that this was the general case in which typical lath martensite was the dominant microstructural feature. Figure 9 shows examples of martensitic microstructure of the coatings.

Orientation imaging microscopy (OIM) was employed to analyze the characteristics of solid state transformation products with special interest in austenite/martensite orientation relationship (OR) and characteristics of the austenite/martensite interphase boundaries. Figure 10 shows examples of grain map, phase map and [001] inverse pole
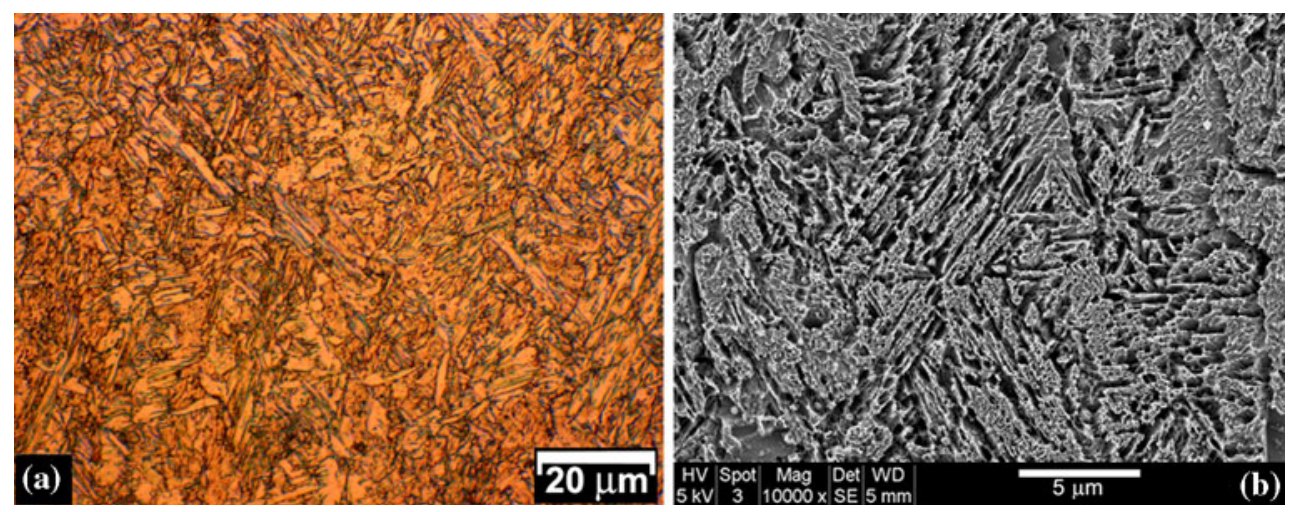

Fig. 9 Lath martensitic microstructure of the deposits observed by (a) optical microscope and (b) SEM 
figure (IPF) map of the studied coatings which are superimposed on image quality (IQ) map (The IQ parameter describes the quality of an electron backscatter diffraction pattern [22]). In these figures, martensite lathes and traces of retained austenite are clearly visible. The data of the images presented in Fig. 10 are used in the subsequent calculations of OR and boundary characteristics.

As the formation of martensite involves coordinated movement of atoms, parent austenite and product martensite always have some form of orientation relationship (OR). Over the years, several models such as KurdjumovSachs (K-S) [23], Nishiyamam-Wassermann (N-W) [24, 25], and Greninger-Troiano (G-T) [26] have been proposed to describe the fcc/bcc OR formed during martensitic transformation. The basic idea in all of these models is that closed-packed planes of the two phases
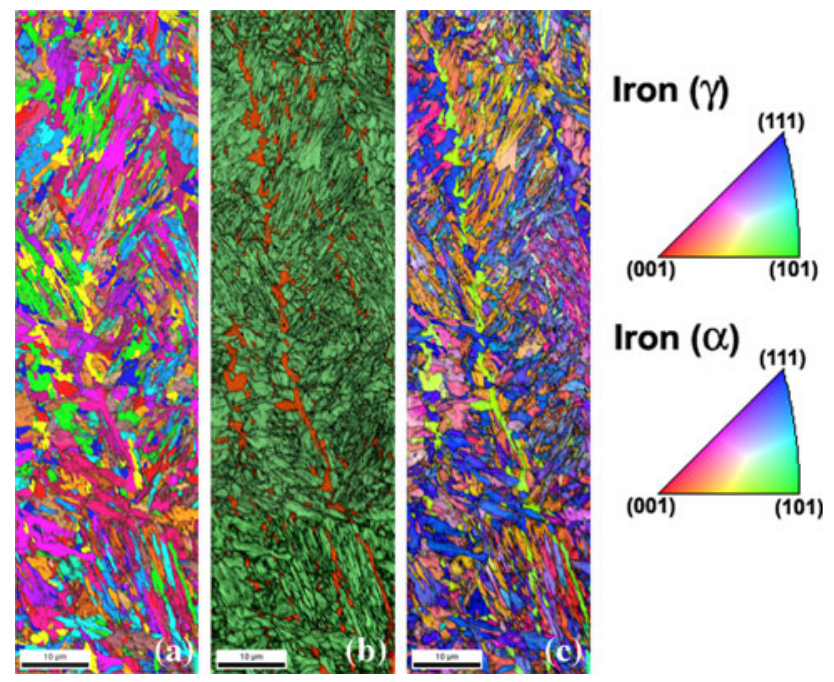

Fig. 10 Examples of OIM scan results obtained from the studied coatings a grain, b phase (martensite: green, austenite: orange), and c [001] inverse pole figure (IPF) maps superimposed on image quality (IQ) map (Color figure online) (i.e., $\{111\}$ for austenite and $\{110\}$ for ferrite) are parallel or nearly parallel. By confirming the validity of the concept of parallel close-packed planes, it will be reliable to use these models to study the OR in our coatings. To explore this task, pole figure (PF) texture plots for close-packed planes of austenite and martensite were obtained and as shown in Fig. 11, it is obvious that the criterion of parallel close-packed planes is valid in our case because the projection of all $\{111\}$ plane poles for austenite coincides with the projection of some $\{110\}$ planes for martensite.

Having this fundamental concept confirmed, discrete PF plots for different planes of austenite and martensite were obtained and their combined PF plot was compared with the theoretical PFs for each OR model. The combined PF plot of the two phases shows close resemblance to the PF of G-T model as shown in Fig. 12.

Usually different austenite-martensite ORs are associated with different values of misorientation across the boundaries between these two phases [27]. Consequently the misorientation across the austenite-martensite boundaries was also studies by OIM to check the existence of G-T orientation relationship. Figure 13 shows a close-up of an area of the images in Fig. 10 containing both martensite and retained austenite.

This section was selected in such a way that it contained only one originally austenite grain (evident from the inverse pole figure map in Fig. 13b) to avoid considering the $\gamma-\gamma$ interfaces in the boundary measurements. By measuring the misorientation angle across interphase boundary, it was known that the two phases are separated by high angle boundaries with misorientation of around $45^{\circ}$. More detailed analysis of the misorientation values showed that there was in fact a range of boundary misorientations from 42 to 46 degrees as highlighted in Fig. $13 \mathrm{~d}$. Highlighting the $42-46^{\circ}$ boundaries in the whole scan area revealed that this is the general case and almost all of the interphase boundaries are high-angle boundaries
Fig. 11 PF texture plots for close-packed planes of $\gamma$ and $\alpha$. Identical location all $\{111\}$ plane poles for $\gamma$ and some $\{110\}$ planes for $\alpha$ confirms that theses two sets of planes are parallel
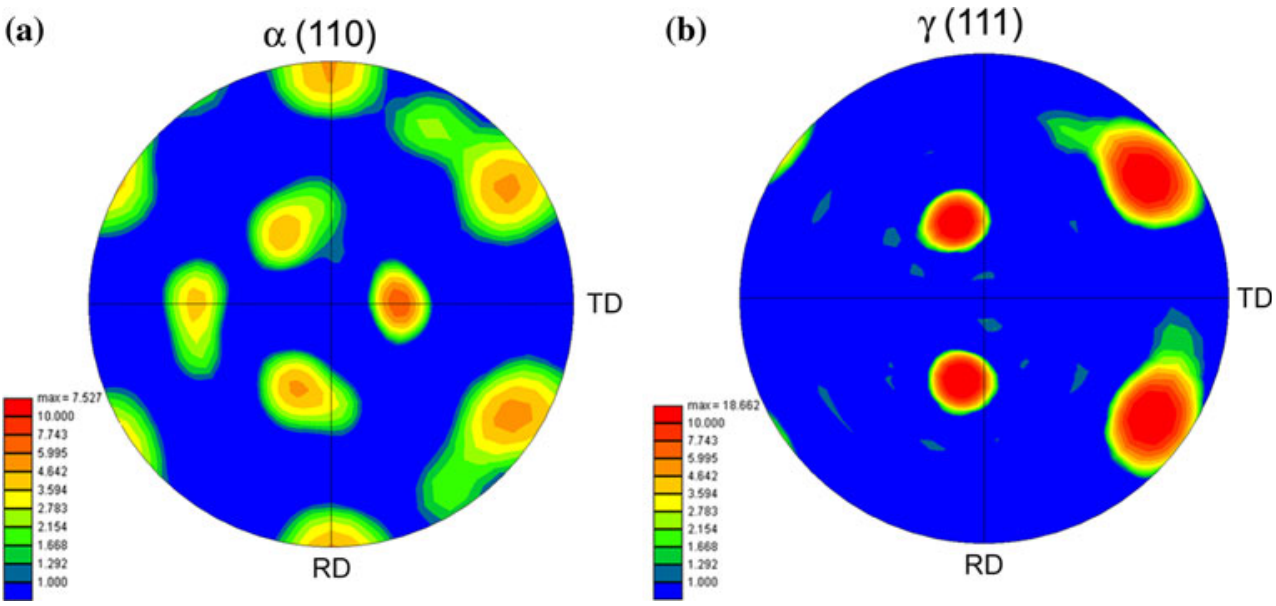
Fig. 12 (100) PF plots obtained for $\mathbf{a} \gamma+\alpha(\gamma$ poles are shown with red dots) and $\mathbf{b}$ fcc/bcc OR in G-T model. Similarity of $\mathbf{a}$ and $\mathbf{b}$ shows the existence of $\mathrm{G}-\mathrm{T}$ orientation relationship between $\gamma$ and $\alpha$ in the studied coating (Color figure online)
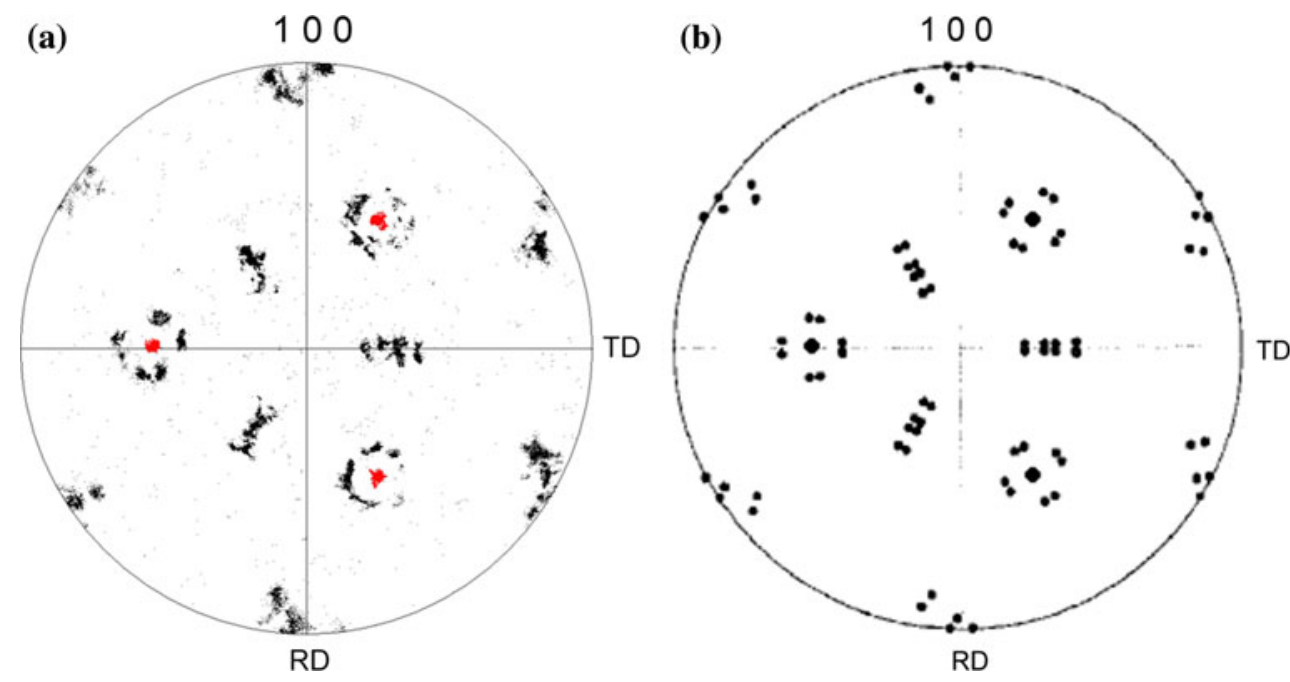

Fig. 13 a section of the phase map containing martensite and only one austenite grain as shown by the single orientation (single color) grain of austenite in [001] IPF of

b. c misorientation angle across the line drawn in a. d $42-46^{\circ}$ boundaries are highlighted
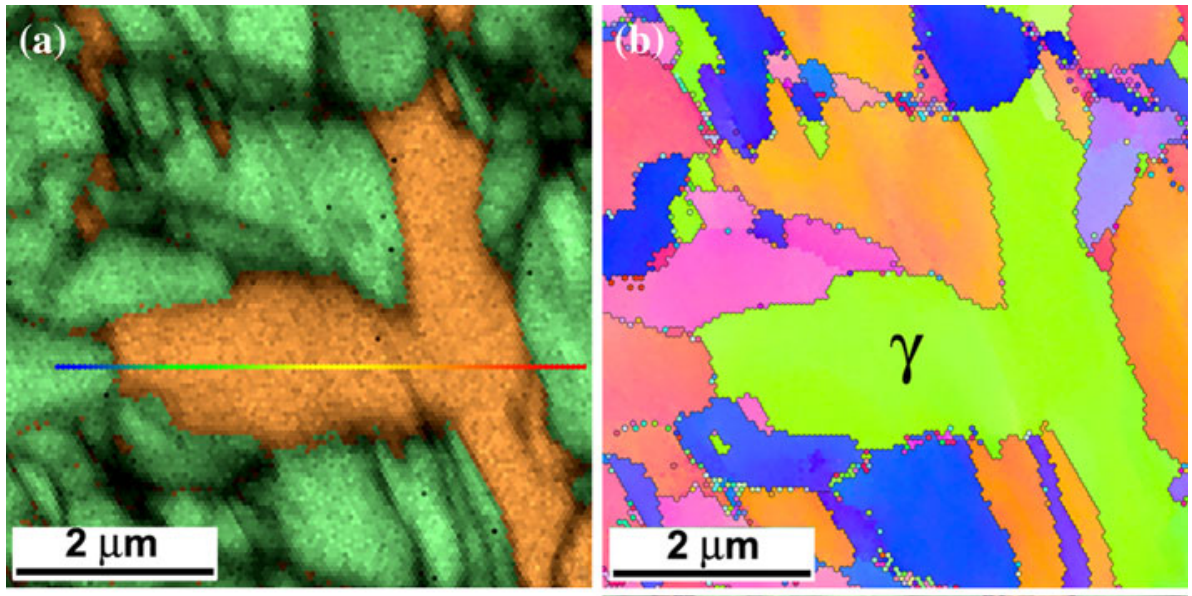

(c)
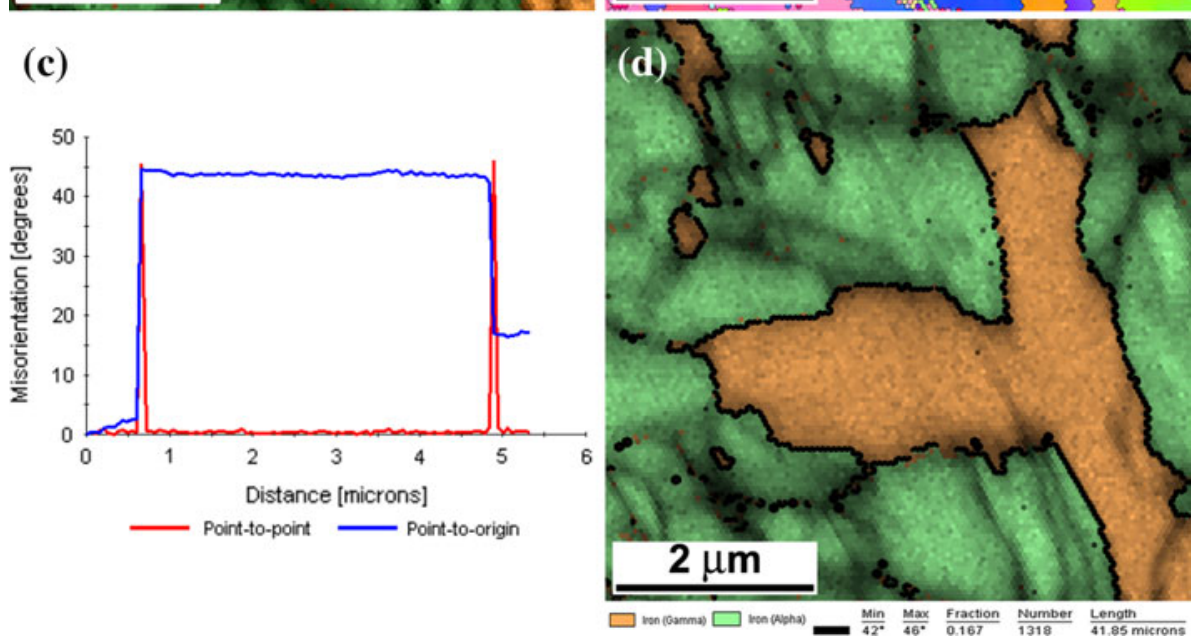

with misorientations in the range of $42-46^{\circ}$ (Fig. 14). Average misorientation angle between austenite and martensite was $44.27^{\circ}$ which is very close to $44.3^{\circ}$ misorientation calculated for $\mathrm{G}-\mathrm{T}$ orientation relationship from Eulerian angles typical of this OR [27]. By repeating the above-mentioned analyses for single and multi layer coatings deposited at the lowest $(5 \mathrm{~mm} / \mathrm{s})$ and the highest
$(117 \mathrm{~mm} / \mathrm{s})$ cladding speeds, it became obvious that different cooling rate associated with various cladding speed had no noticeable effect on boundary characteristics or OR in the final structure of the coatings.

On the other hand, EBSD results showed that while in multi layer deposits the amount of retained austenite was around $4 \%$ for all cladding speeds, in single layer coatings 
Fig. $1442-46^{\circ}$ boundaries highlighted in the whole scan area showing that misorientations of nearly all interphase boundaries are in this range (Color figure online)
Fig. 15 Effect of cladding speed on hardness values in a multi layer and $\mathbf{b}$ single layer deposits
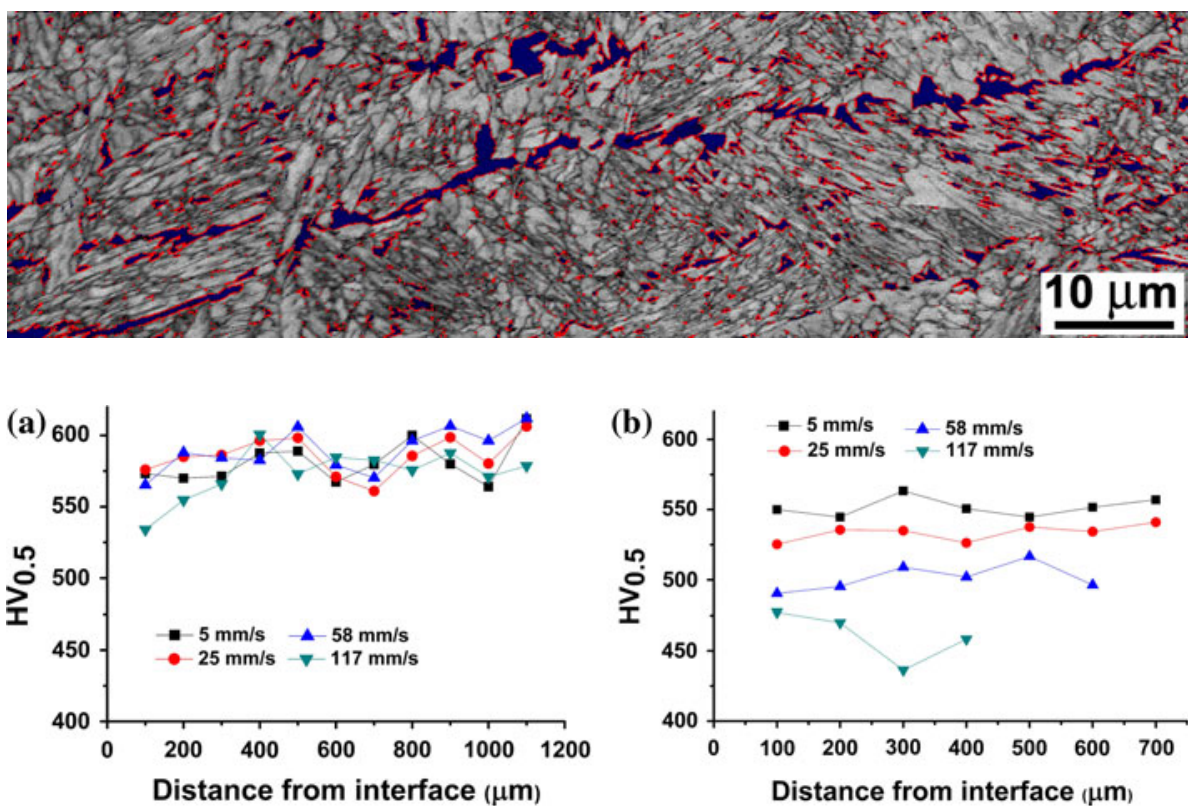

more austenite (up to $11 \%$ ) was retained at the higher cladding speed. This results in a variation of hardness values of single layer deposits produced at different scanning speeds as shown in Fig. 15a but in multi layer coatings, hardness values were the same in all cases (Fig. 15b). The observed differences can be attributed to the austenite stabilizing effect of finer dendrites produced at higher cladding speeds [13].

\section{Conclusions}

AISI 431 martensitic stainless steel was deposited by fiber laser at four different cladding speeds up to $117 \mathrm{~mm} / \mathrm{s}$. Solidification structure of the deposits mostly consisted of dendritic structure, but CET was observed at the top of multi layer claddings. Higher cladding speeds resulted in finer dendritic structures with cell spacing values down to around $9 \mu \mathrm{m}$ in multi-layer and $3 \mu \mathrm{m}$ in single layer deposits. Formation of $\delta$ phase which was distributed heterogeneously with higher concentration at track boundaries was suppressed by higher cladding speeds as a result of faster growth kinetics of $\gamma$. In addition, homogenous distribution of alloying elements across dual phase areas consisting of former $\gamma$ plus $\delta$ showed that solidification of these deposits occurred in a partitionless manner. Finally, cooling in the solid phase produced lath martensitic structure having $42-46^{\circ}$ high angle boundaries and G-T orientation relationship with retained austenite. Morphology, orientation relationship and boundary misorientation angle of martensite produced in samples with different cladding speeds did not show big differences, but the amount of retained austenite was increased by increasing the cladding speed with a maximum of around 11 percent in single layer coating deposited at $117 \mathrm{~mm} / \mathrm{s}$. This austenite stabilizing effect of high speed cladding reduced the hardness values of the samples with the most refined microstructures. This finding is in contrast to the behavior reported for precipitation-hardening alloy systems.

Acknowledgements The work is part of the research program of M2i (Materials innovation institute), The Netherlands, Project number: MC7.06259. M. Dutka is acknowledged for his assistance in laser experiments.

Open Access This article is distributed under the terms of the Creative Commons Attribution Noncommercial License which permits any noncommercial use, distribution, and reproduction in any medium, provided the original author(s) and source are credited.

\section{References}

1. Dearnley PA, Smith GA (2004) Wear $256: 491$

2. Blawert C, Weisheit A, Mordike BL, Knoop RM (1996) Surf Coat Technol 85:15

3. David SA, Vitek JM, Hebble TL (1987) Weld J 66:289

4. Kurz W, Trivedi R (1994) Mater Sci Eng A 179-180:46

5. Kathuria YP (2000) Surf Coat Technol 132:262

6. Ellemann R, Guesnier A Preparation of ferrous metals for electron backscatter diffraction (EBSD) analysis. http://www.struers. com/resources/elements/12/108620/Application_Note_EBSD_ English.pdf. Accessed Sept 2010

7. Ryde L (2006) Mater Sci Technol 22:1297

8. Metals handbook, vol 1, 10 edn, 4th printing. ASM International, Materials Park, p 843

9. Kou S (2003) Welding metallurgy, 2nd edn. Wiley, New Jersey

10. Kurz W, Bezencon C, Gaumann M (2001) Sci Technol Adv Mater 2:185 
11. Bontha S, Klingbeil N, Kobryn P, Fraser H (2009) Mater Sci Eng A 513-514:311

12. Hofman J (2009) Development of an observation and control system for industrial laser cladding. $\mathrm{PhD}$ thesis, University of Twente, The Netherlands, pp 121-126

13. Colaço R, Vilar R (2004) Mater Sci Eng A 385:123

14. Kurz W, Fisher DJ (1992) Fundamentals of solidification, 3rd edn. Trans Tech Publications, Switzerland

15. Metals handbook, vol 6, 10 edn, 4th printing. ASM International, Materials Park, p 678

16. Elmer JW, Allen SM, Eagar TW (1989) Metal Trans A 20:2117

17. Zambon A, Bonollo F (1994) Mater Sci Eng A 178:203
18. Vitek JM, David S (1994) In: Mazumder J, Mukerjee K, Mordike BL (eds) Laser mater process IV. AIME, Warrendale, pp 153-167

19. Fukumoto S, Kurz W (1998) ISIJ Int 38:71

20. Kelly TF, Cohen M, VanderSande JB (1989) Metal Trans A 15:819

21. (1995) Heat treater's guide: practices and procedures for irons and steels, 2nd edn. ASM International, Materials Park

22. Wright SI, Nowel MM (2006) Microsc Microanal 12:72

23. Kurdjumow G, Sachs G (1930) Z Phys 64:325

24. Nishiyama Z (1934) Sci Rep Tohoku Imp Univ Tokyo 26:637

25. Wassermann G (1935) Mitt K-Wilh-Inst Eisenforsch 17:149

26. Greninger AB, Troiano AR (1949) J Met Trans 185

27. Nolze G (2006) Cryst Res Technol 41:72 